patients scoring $\leq 10 \mathrm{~mm}(16.1 \%)$, corresponding to a difference of up to $4.7 \%$ versus other PGAs. Similar results were found for the $\leq 20$ cut-off (Table 1 ). By using different PGA's formulations the rates of remission calculated with different indices can vary between $4.7 \%$ and $6.7 \%$ (Table 2).

Bland-Altman chart confirmed the low agreement between ACR/EULAR formulation and the other PGA formulations $(\mathrm{p}<.05)$, except for the DAS "general health" $(p=.054)$.

Table 2. Remission rates according to four composite indexes with the 6 PGA's formulations $(\mathrm{n}=193)$

\begin{tabular}{lcccc}
\hline PGA Formulation & \multicolumn{4}{c}{ Definition $-\mathrm{n}(\%)$} \\
\cline { 2 - 5 } & ACR/EULAR Boolean & SDAI & CDAI & DAS28 4vCRP \\
\hline v1 Reuma.pt & $19(9.8)$ & $32(16.8)$ & $33(17.1)$ & $97(50.5)$ \\
v2 ACR/EULAR & $25(13.0)$ & $36(19.1)$ & $39(20.0)$ & $100(51.7)$ \\
v3 CDAI/SDAI & $16(8.3)$ & $27(14.1)$ & $26(13.5)$ & $91(47.3)$ \\
v4 DAS28-GH & $20(10.4)$ & $29(15.2)$ & $33(17.1)$ & $99(51.4)$ \\
v5 DAS28-DA & $19(9.8)$ & $29(15.2)$ & $30(15.5)$ & $100(51.7)$ \\
v6 Investigators & $17(8.8)$ & $27(14.1)$ & $27(14.0)$ & $97(50.0)$ \\
Max. dif. within definition & $9(4.7)$ & $9(4.7)$ & $13(6.7)$ & $9(4.7)$ \\
\hline
\end{tabular}

Conclusions: The use of different PGA formulations has clinical implications in disease activity, which, in turn, can influence therapeutic decisions. The establishment of a single standardised formulation seems warranted.

Disclosure of Interest: None declared

DOI: 10.1136/annrheumdis-2017-eular.5518

\section{THU0146 QUALITY OF LIFE IN PATIENTS WITH RHEUMATOID ARTHRITIS - DEMOGRAPHIC AND SOCIO-ECONOMIC ASSOCIATIONS}

H. Baharuddin ${ }^{1}$, N. Zainudin ${ }^{2}$, H. Mohd Yusoof ${ }^{2}$, I.S. Lau ${ }^{2} .{ }^{1}$ Rheumatology, Universiti Teknologi MARA; ${ }^{2}$ Rheumatology, Hospital Selayang, Selangor, Malaysia

Background: The primary goal of treating patients with rheumatoid arthritis (RA) is to maximise long-term HRQol. ${ }^{1}$ Quality of life (Qol) in patients with RA may be substantially impacted by their inability to perform daily activities, a shift in family roles, more restricted employment opportunities, increased financial burden and social dependency and reduced recreational activities. ${ }^{2}$

Objectives: To investigate the Qol among RA patients and its association with demographic and socioeconomic details.

Methods: This is a cross-sectional study conducted in a rheumatology outpatient clinic in Malaysia. Patients who fulfilled 2010 ACR/ EULAR classification criteria for RA were asked to answer WHOQOL-BREF questionnaire and specific questions on demographics and socio-economic details, during their attendance to rheumatology clinics. WHOQOL-BREF is a self-report quality of life questionnaire on individual's perception of quality of life and health, physical health, psychological, social relationships and environment domains.

Data was analysed using SPSS 20. Student's t-test was used to analyse the mean difference between two groups and chi-square test was used to analyse between 2 categorical data. Pearson correlation was used to analyse correlation between two groups of continuous data. $p<0.05$ was considered significant.

Results: The mean age of patients in this study was $53.10( \pm 14.3)$ years, with majority being females $(80.4 \%)$ and married $(70.6 \%)$. Half of the patients were Malays (49.0\%). 51.0\% rated overall quality of life as good and $41.2 \%$ rated overall health as satisfied. The mean transformed scores were $55.2( \pm 15.9)$ in physical health, $57.3( \pm 15.9)$ in psychological, $59.2( \pm 18.1)$ in social relationships and $58.2( \pm 15.2)$ in environment domains.

There were significant differences in the transformed scores for Malay (65.5 \pm 15.9$)$ and non-Malay $(53.1 \pm 18.2)$ in the social relationship domain; $t(49)=2.58, p=0.01$, and for education at secondary level and above $(65.9 \pm 14.9)$ and primary level (48.0 \pm 16.6$), t(49)=-3.87, p<0.01$. We found no significant association between race and education level; $17(53.1 \%)$ Malays and $15(46.9 \%)$ non-Malays had education level of secondary and higher, $X^{2}(1, N=51)=0.58, p=0.48$. Patients with household income of less than RM 3, 000 had significantly lower scores compared to those with higher household income, in overall perception of quality of life $(3.3 \pm 0.9$ vs $4.0 \pm 0.6 ; t(49)=-2.8, p<0.01)$, overall perception of health $(2.9 \pm 0.9$ vs $3.6 \pm 0.7, t(49)=-2.97, p<0.01)$, physical health domain $(51.2 \pm 16.2$ vs $63.8 \pm 11.6, t(49)=-2.78, p=0.01)$ and psychological domain $(53.3 \pm 16.3$ vs $66.1 \pm 10.9, t(49)=-2.85, p=0.01)$.

Conclusions: Patients with RA perceived their Qol to be moderate in all domains. Social relationship was perceived to be better in Malays and patients with higher educational level. Low income was significantly associated lower overall quality of life and health, physical and psychological health.

References:

[1] Smolen JS, Breedveld FC, Burmester GR et al. Treating rheumatoid arthritis to target: 2014 update of the recommendations of an international task force. Ann Rheum 2015; 0, 1-13.

[2] Matcham F, Scott IC, Rayner L et al (2014). The impact of rheumatoid arthritis on quality-of-life assessed using the SF-36: A systemic review and meta-analysis. Seminars in Arthritis and Rheumatism 2014; 44: 123-130.

Disclosure of Interest: None declared

DOI: 10.1136/annrheumdis-2017-eular.7026

\section{THU0147 THORAX CT FINDINGS IN A LARGE COHORT OF PATIENTS WITH RHEUMATOID ARTHRITIS: HUR-BIO REAL LIFE RESULTS}

A. Sari, B. Armagan, A. Erden, L. Kilic, O. Karadag, A. Akdogan, S. Apras Bilgen, I. Ertenli, U. Kalyoncu, S. Kiraz. Rheumatology, Hacettepe University School of Medicine, Ankara, Turkey

Background: Lungs are one of the target organs in rheumatoid arthritis (RA) patients. Interstitial lung disease (ILD), rheumatoid nodules, pleural effusion, bronchiectasia and small airway disease are common manifestations of lung involvement.

Objectives: Objective of this study was to evaluate distribution of Thorax CT findings and treatment features in RA patients registered in a biologic registry.

Methods: HUR-BIO (Hacettepe University Rheumatology Biologic Registry) is a prospective, single center database of biological treatments including 1229 RA patients by August 2016. Demographics, clinical and serological features of patients and thorax CT results performed in Hacettepe University between 2000 and 2016 were retrospectively evaluated. Patients whose CT was reported as small airway disease or ILD by radiologists, were evaluated as a subgroup. Data included type of biological treatments before diagnose of ILD and at last control as well.

Results: Among 1229 patients (78.8\% female), mean age was $53.3 \pm 12.9$ and disease duration was $11.4 \pm 7.9$. Thorax CT had been performed in $203(16.5 \%)$ patients. Distribution of pathologic findings in thorax CT was represented in Table 1. 29 patients $(\% 2.4)$ were diagnosed as ILD with regard to CT findings. Patients with ILD were older $(64.5 \pm 6.7$ vs $60.6 \pm 10.1, \mathrm{p}=0.039)$ and more frequently positive for rheumatoid factor (RF) $(25 / 27$ (\%92.6) vs 77/121 (\%63.3), $p=0.003)$ than patients without ILD. ILD was detected before beginning of biologics in $11(37.9 \%)$ patients and during biologic treatment in $18(62.1 \%)$ patients. Honeycombing was seen in $10(34.5 \%)$ patients. First choice of biologic agent was RTX in $10(34.5 \%)$ and TNFi in 19 (65.5\%) patients. In ILD patients, mean follow-up duration was $51 \pm 31$ months and first biologic was switched to another in $16(55.2 \%)$ of patients. At the last follow-up visit $19(65.5 \%)$ patients were on rituximab, $3(10.3 \%)$ patients were on abatacept and $7(24.1 \%)$ were on TNFi. Small airway disease was detected in $19(9.3 \%)$ patients. History of smoking was present in only $4(21.0 \%)$ of patients with small airway disease.

Table 1. Distribution of thorax CT findings

\begin{tabular}{lc}
\hline Thorax CT finding & $\mathrm{N}(\%)$ \\
\hline Interstitial thickening & $13(6.4)$ \\
Reticular densities & $31(15.3)$ \\
Ground glass opacities & $33(16.3)$ \\
Nodules & $35(17.3)$ \\
Effusion & $18(8.9)$ \\
Bronchiectasia & $46(22.7)$ \\
Traction bronchiectasia & $17(8.4)$ \\
\hline
\end{tabular}

Conclusions: Bronciectasia, rheumatoid nodules, small airway disease and ILD were the most frequent CT findings of RA patients. Rituximab was the choice of first biologic treatment in one third of patients, however two-thirds of patients were on rituximab therapy at the last follow-up visit. Lung involvement stands out as an important factor in selection of biologics.

Disclosure of Interest: None declared

DOI: 10.1136/annrheumdis-2017-eular.4076

\section{THU0148 INCREASE OF NIGHT QT-INTERVAL DURATION IN RHEUMATOID ARTHRITIS PATIENTS TREATED WITH TOFACITINIB DURING 12-MONTH FOLLOW-UP}

I.G. Kirillova, D. Novikova, E. Luchikhina, E. Markelova, H. Udachkina,

N. Demidova, A. Misiyuk, T. Popkova, A. Volkov, L. Denisov, D. Karateev. V.A. Nasonova Research Institute of Rheumatology, Moscow, Russian Federation

Objectives: to evaluate dynamic of ECG parameters in RA pts treated with tofacitinib (TOFA) during 12-month follow-up.

Methods: After 12-m follow-up the ECG parameters by 12 lead ECG and $24 \mathrm{~h}$ ECG was assessed in 28 RA pts treated with TOFA (22 women, median age $54[40 ; 62]$ years, disease duration $39,5[16,5 ; 60,0] \mathrm{m}$, moderate to high activity (DAS28-5.1 [4.6;6.0], SDAl-26 (21;34)), positive for ACCP $(75 \%) / R F(79 \%)$, who were non-responders to MTX at least $15 \mathrm{mg} /$ week and/or other synthetic DMARDs and bDMARDs. TOFA therapy was started in all pts with dose 5 $\mathrm{mg}$ BID per os followed by the dose escalation to $10 \mathrm{mg}$ BID in $8(29 \%)$ pts. TOFA used in combination with MTX in 27 (96\%) pts, leflunomide in 1 (4\%). Low-dose oral corticosteroids ( $<10 \mathrm{mg} /$ day prednisone or equivalent) were received by $9(35 \%)$ pts. Remission or LDA was achieved in $55 \%$ pts (DAS28), $77 \%$ (SDAI). At baseline the most of pts had multiple CVRF and subclinical organ damage (arterial hypertension-67\%, overweight- $57 \%$, abdominal obesity- $61 \%$, physical inactivity-64\%, smokers/ex-smokers-25\%/21\%, menopausal status-59\%, DM type $2-7 \%$, mSCORE $\geq 5 \%>21 \%$, subclinical carotid atherosclerosis- $64 \%$, cardiac heart failure with preserved ejection fraction-7\%. Cardioprotective therapy received $16(57 \%)$ pts (beta-blockers-7, angiotensin II receptor type 2/ACE inhibitors-11, statins-11, dihydropyridine calcium channel blockers-7).

Results: There was no difference in heart rate $(\mathrm{HR})$, QTc interval duration, 
QRS duration measured by 12-lead ECG in RA pts treated with TOFA (table 1). However, an increase in $P Q$ interval duration was observed $(p=0,04)$. There were significantly decrease of mean $\operatorname{HR}(p<0,003)$, increase of QRS duration $(p<0,03)$, QTc $(p<0.03)$, night QTc $(p<0,02)$ in 24 h ECG ambulatory recording. $H R, P Q$, QTc duration were changed independently of beta-blockers therapy. The number of pts with QTc $\geq 440 \mathrm{~ms}$ increased from $11 \%$ to $21 \%(p>0.05)$. A change in QTc duration correlated negatively with dynamics of DAS 28 , SDAI $(r=-0,4, p<0,05)$, DM $(r=0,5, p<0,02), d B P(r=-0,4, p<0,04)$. There were also significantly increase number of ventricular premature beats $(p<0,03)$.

Table 1. ECG characteristics of pts with RA treated with TOFA

\begin{tabular}{lcc}
\hline & Baseline & After 12 months \\
\hline 12-lead ECG & $71[64 ; 81]$ & \\
Heart rate, bpm & $133[126 ; 131]$ & $69[61 ; 78]$ \\
PQ, ms & $83[79 ; 89]$ & $150[130 ; 160]^{\star}$ \\
QRS, ms & $421[406 ; 434]$ & $84[80 ; 91]$ \\
QTc, ms & $78[70 ; 84]$ & $410[398 ; 420]$ \\
24 h ECG & $82[73 ; 91]$ & $74[65 ; 80]^{\star}$ \\
Heart rate, bpm & $409[402 ; 425]$ & $85[73 ; 92]^{\star}$ \\
QRS, ms & $414[400 ; 434]$ & $415[406 ; 427]^{*}$ \\
QTc, ms & $18(66)$ & $420[408 ; 437]^{*}$ \\
QTc night, ms & $14[7 ; 50]$ & $22(78)$ \\
VPB pts, $n$ (\%) & $280[15 ; 3423]^{\star}$ \\
Ventricular premature beats, $n$ &
\end{tabular}

Data are presented in median values and IR (unless otherwise noted), ${ }^{*} \mathrm{p}<0,05$ before and after TOFA treatment (nonparametric paired Wilcoxon test).

Conclusions: A significant decrease in HR and an increase in QRS, night QTc interval duration, number of ventricular premature beats by $24 \mathrm{~h}$ ECG were observed in RA pts treated with tofacitinib (TOFA) during 12-month follow-up. QTC duration correlated with dynamic of disease activity, DM type 2 and diastolic BP. Disclosure of Interest: None declared

DOI: 10.1136/annrheumdis-2017-eular.5119

\section{THU0149 A CLINICAL AND PATHOLOGICAL CHARACTERIZATION OF METHOTREXATE-ASSOCIATED LYMPHOPROLIFERATIVE DISORDERS IN PATIENTS WITH RHEUMATOID ARTHRITIS}

K. Nakano ${ }^{1}$, A. Nawata ${ }^{1,2}$, S. Nakayamada ${ }^{1}$, S. Iwata $^{1}$, K. Hanami $^{1}$, S. Kubo ${ }^{1}$ I. Miyagawa ${ }^{1}$, M. Yoshikawa ${ }^{1}$, K. Saito ${ }^{1}$, Y. Tanaka ${ }^{1} .{ }^{1}$ The First Department of Internal Medicine; ${ }^{2}$ Department of Pathology, University of Occupational and Environmental Health, Japan, Kitakyushu, Japan

Background: Methotrexate (MTX) is used as an anchor drug for the treatment of rheumatoid arthritis (RA). Patients with RA have a modestly increased risk of developing lymphoproliferative disorders (LPD). Furthermore, although sometimes spontaneous regression occurs after withdrawal of MTX, LPD developed during the treatment with MTX is broadly defined as MTX-associated LPD (MTX-LPD). Objectives: To characterize the risk factors concerning MTX-LPD and to consider optimal treatment after occurrence of LPD in patients with RA.

Methods: We retrospectively evaluated 51 RA patients with LPD from 2006 to 2015 in our institution. MTX-LPD patients were divided into two groups; regressive LPD after MTX cessation ( $N=27)$ and persistent LPD though MTX was tapered $(\mathrm{N}=24)$, and the clinical characteristics, pathology and treatment outcomes were compared. EBV infection and IL-6 receptor (IL-6R) expression were analyzed by in situ hybridization and immunohistochemistry.

Results: There was no significant difference in disease duration, stage, disease activity of RA, the positive rate of Epstein-Barr virus-encoded small RNAs, EBERs (42.7 vs $50.0 \%$ ) and treatment with TNF-inhibitors (40.7 vs $45.8 \%$ ) between regressive LPD and persistent LPD. Age of LPD onset (59.1 vs 68.3), CRP (2 vs $5 \mathrm{mg} / \mathrm{dl}$ ) and the weekly MTX dose (10.9 vs $8.4 \mathrm{mg} / \mathrm{w}$ ) significantly differed between the groups. Of note, IL-6R was highly expressed in both group (75.0 vs $66.7 \%$ ). Among regressive LPD, 3 patients developed DLBCL later. persistent LPD showed poorer prognosis and worse mortality than regressive LPD. An older age and anemia were poor prognostic factors. Of 51 patients, $41 \%$ achieved sustained low disease activity (LDA) with other DMARDs except MTX. Nine of 10 patients refractory to DMARDs were controlled by tocilizumab (TCZ) and kept LDA.

Conclusions: Taken together, it seems unreasonable to be lump the persistentgroup into the same category as MTX-LPD. The high expression rate of IL-6R and the high responsiveness to TCZ suggest that IL-6/IL-6R is likely to play a role in the development of LPD in patients with RA.

Disclosure of Interest: K. Nakano: None declared, A. Nawata: None declared, S. Nakayamada: None declared, S. Iwata: None declared, K. Hanami: None declared, S. Kubo Speakers bureau: Bristol-Myers, I. Miyagawa: None declared, M. Yoshikawa: None declared, K. Saito: None declared, Y. Tanaka Grant/research support from: Mitsubishi-Tanabe, Takeda, Daiichi-Sankyo, Chugai, Bristol-Myers, MSD, Astellas, Abbvie, Eisai, Consultant for: Abbvie, Chugai, Daiichi-Sankyo, Bristol-Myers, Mitsubishi-Tanabe, Astellas, Takeda, Pfizer, Teijin, Asahi-kasei, YL Biologics, Sanofi, Janssen, Eli Lilly, GlaxoSmithKline, Speakers bureau: Abbvie, Chugai, Daiichi-Sankyo, Bristol-Myers, Mitsubishi-Tanabe, Astellas, Takeda, Pfizer, Teijin, Asahi-kasei, YL Biologics, Sanofi, Janssen, Eli Lilly, GlaxoSmithKline DOI: 10.1136/annrheumdis-2017-eular.4660

\section{THU0150 OPTIMIZING COMORBIDITY RISK MANAGEMENT IN RA BY TRANSLATING A NURSE-LED INTERVIEW INTO AN EASILY INTERPRETABLE TRAFFIC LIGHT SYSTEM}

K. Krüger ${ }^{1}$, R. Eder ${ }^{2}$, C. Müller ${ }^{3}$, R. Hecker ${ }^{3} \cdot{ }^{1}$ Rheumatologisches Praxiszentrum St. Bonifatius, München; ${ }^{2}$ Rheumapraxis am Spitaltor, Deggendorf; ${ }^{3}$ Abbvie Deutschland Gmbh \& Co. Kg, Wiesbaden, Germany

Background: Due to its inflammatory nature, rheumatoid arthritis (RA) is associated with a variety of comorbidities and individual risk factors [1]. The benefit of a nurse-led programme on RA comorbidity management has been reported recently [2].

Objectives: To describe a new assessment tool for patient risk management and report the difference between structured versus expert guided assessment following standard of care in a construct-validation cohort.

Methods: The ongoing cluster randomized multicentre study ERIKO is longitudinally assessing individual risk profiles of patients with RA in Germany. The aim of this study is to test the benefit of applying a nurse-led scoring algorithm for individual risk profiles followed by a structured patient consultation (active arm) as compared to local standard of care.

The ERIKO-Score was calculated by rating validated assessment tools and treatment guidelines and translating their outcome into a three-level ordinal score defined by the categories low, intermediate or high risk, including nominal weights for risk management (e.g. condition is being treated with goals achieved or not). Scores were interpreted numerically by rating categories with 0,1 and 2 points, respectively.

We included cardiovascular (CV) risk (ESC-guideline), infection risk (RABBIT risk calculator), vaccination status (guideline), fracture risk (FRAX), tooth status (PSI), depression- (PHQ-9) and health-related quality of life (hrQoL, RAID). The same risk categorization was prompted in all centres at the screening visit without providing the rating tools.

This analysis compares $\mathrm{SOC}$ ratings from the screening visit (month zero) with the baseline ERIKO-scores at month three in the active arm. No statistical hypothesis testing was performed in this analysis.

Results: This analysis included 283 patients from 31 centres specialized in rheumatology care randomized to the active study arm. $82.3 \%$ were female with a mean age of 57.8 years (sd 12.1) and a mean DAS28 of 2.6 (sd 1.1). The mean total ERIKO-Score was slightly higher at baseline as compared to applying the scoring algorithm on SOC ratings at the screening visit ( $5.33+-1.95$ vs. 4.32 +- 2.61, respectively, table 1). The discrepancy was mainly driven by CV risk, vaccination status, tooth status and depression risk, that were more often rated worse by applying the ERIKO score than by SOC, while infection- and fracture risk were more frequently rated lower by the ERIKO-Score (table 2). The strongest discrepancy between SOC ratings and ERIKO-Score ( $\Delta=2$ points) were observed for tooth status ( $\mathrm{N}=54), \mathrm{CV}$ risk $(\mathrm{N}=25)$ and vaccination status $(\mathrm{N}=25)$ (table 2). SOC ratings were strongly based on expert opinion with the most frequently cited tools being vaccination guidelines $(38.9 \%)$, bone mineral density measurement (BMD) $(39.6 \%)$ and RABBIT-infection risk-score (23.1\%).

\begin{tabular}{|c|c|c|c|c|c|c|c|c|}
\hline \multicolumn{2}{|l|}{$N=283^{\circ}$} & \multicolumn{5}{|c|}{ Ordinal Risk Rating } & \multicolumn{2}{|c|}{ Numeric interpretation } \\
\hline Dimension & $\begin{array}{l}\text { missing } \\
{[\%(N)]}\end{array}$ & $\begin{array}{l}\text { Low } \\
{[\%(N)]}\end{array}$ & \multicolumn{2}{|c|}{$\begin{array}{c}\text { Intermediate } \\
{[\%(N)]}\end{array}$} & \multicolumn{2}{|c|}{$\begin{array}{l}\text { High } \\
{[\%(N)]}\end{array}$} & $\begin{array}{l}\text { Median } \\
\text { (IQR) }\end{array}$ & Mean (sd) \\
\hline$\overline{C V}$ risk & $9.2(26)$ & $27.9(79)$ & \multicolumn{2}{|c|}{$26.5(75)$} & \multicolumn{2}{|c|}{$36.4(103)$} & $1(2)$ & $1.1(0.80)$ \\
\hline $\begin{array}{l}\text { Vaccination } \\
\text { status }\end{array}$ & $9.2(26)$ & $15.9(45)$ & \multicolumn{2}{|c|}{$50.5(143)$} & \multicolumn{2}{|c|}{$24.4(69)$} & $1(1)$ & $1.1(0.66)$ \\
\hline Infection risk & $9.2(26)$ & $79.9(226)$ & \multicolumn{2}{|c|}{$10.2(29)$} & \multicolumn{2}{|c|}{$0.7(2)$} & $0(0)$ & $0.1(0.36)$ \\
\hline $\begin{array}{l}\text { Risk of major } \\
\text { osteoporotic } \\
\text { fracture }\end{array}$ & $9.9(28)$ & $527(149)$ & \multicolumn{2}{|c|}{$32.9(93)$} & \multicolumn{2}{|c|}{$4.6(13)$} & $O(1)$ & $0.5(0.59)$ \\
\hline Tooth status & $11.3(32)$ & $5.3(15)$ & \multicolumn{2}{|c|}{$55.1(156)$} & \multicolumn{2}{|c|}{$28.3(80)$} & 1 (1) & $1.3(0.56)$ \\
\hline $\begin{array}{l}\text { Depression } \\
\text { risk }\end{array}$ & $9.2(26)$ & $46.3(131)$ & \multicolumn{2}{|c|}{$39.6(112)$} & \multicolumn{2}{|c|}{$4.9(14)$} & $O(1)$ & $0.5(0.60)$ \\
\hline hrQol & $9.2(26)$ & $33.9(96)$ & \multicolumn{2}{|c|}{$47.3(134)$} & \multicolumn{2}{|c|}{$9.5(27)$} & $1(1)$ & $0.7(0.64)$ \\
\hline \multicolumn{9}{|c|}{$\mathrm{n}=26$ without data at baseline } \\
\hline \multicolumn{7}{|c|}{$\begin{array}{l}\text { Table } 2 \text { Discrepancy between ERIKO-Score and ratings following SOC (baseline vs. screening) } \\
\Delta=1 \text { or } 2 \text { points (total) }\end{array}$} & \multicolumn{2}{|c|}{$\begin{array}{l}\Delta=2 \text { points } \\
\text { (low vs. high) }\end{array}$} \\
\hline \multicolumn{2}{|l|}{ Dimension } & \multicolumn{2}{|c|}{$\begin{array}{c}\text { No } \\
\text { difference }\end{array}$} & \multicolumn{2}{|c|}{$\begin{array}{l}\text { SOC risk } \\
\text { lower }\end{array}$} & $\begin{array}{l}\text { SOC risk } \\
\text { higher } \\
{[\%(N)]}\end{array}$ & $\begin{array}{l}\text { SOC risk } \\
\text { lower } \\
{[\%(N)]}\end{array}$ & $\begin{array}{l}\text { SOC risk } \\
\text { higher } \\
{[\%(N)]}\end{array}$ \\
\hline \multicolumn{2}{|l|}{ CV risk } & $\frac{[\%(N)]}{350(99)}$ & $35.0(99)$ & \multicolumn{2}{|c|}{$44.2(125)$} & $10.2(29)$ & $8.5(24)$ & $0.4(1)$ \\
\hline \multicolumn{2}{|c|}{ Vaccination status ${ }^{\circ}$} & \multicolumn{2}{|c|}{$34.6(98)$} & \multicolumn{2}{|c|}{$38.5(109)$} & $17.7(50)$ & $7.4(21)$ & $1.4(4)$ \\
\hline \multicolumn{2}{|l|}{ Infection risk ${ }^{\circ}$} & $63.6(1$ & & 6.011 & & $21.2(60)$ & 0 & $3.2(9)$ \\
\hline $\begin{array}{l}\text { Risk of major o } \\
\text { fracture }\end{array}$ & oporotic & 36.811 & & 15.214 & & $38.9(110)$ & $1.4(4)$ & $3.5(10)$ \\
\hline Tooth status" & & $18.4 !$ & & $47.7(1)$ & & $23.3(66)$ & $15.5(44)$ & $3.5(10)$ \\
\hline Depression rist & & 48.411 & & 30.718 & & $11.7(33)$ & $3.2(9)$ & $3.2(9)$ \\
\hline hrQol $^{\circ}$ & & 64.611 & & 18.015 & & $14.1(40)$ & $2.1(6)$ & $0.4(1)$ \\
\hline
\end{tabular}

Conclusions: A nurse-led comorbidity risk assessment in rheumatology practices seems feasible. Applying the ERIKO-Score based on validated tools led to a 